\title{
Topical proparacaine vs combined topical-intracameral lidocaine anesthesia in phacoemulsification surgery with preoperative counseling about intraoperative visual fear
}

Kiran Shakya ${ }^{1}$, Sangita Shakya ${ }^{2}$, Ram Prasad Pokhrel ${ }^{3}$, Om Krishna Malla ${ }^{4}$

${ }^{1}$ Assistant Professor; Department of Ophthalmology, Kathmandu Medical College Teaching Hospital, Kathmandu, Nepal.

${ }^{2}$ Sangita Shakya, Lecturer, Department of pharmacy, NIST College, Kathmandu, Nepal.

${ }^{3}$ Ram Prasad Pokhrel, Professor; Department of Ophthalmology, Kathmandu Medical College

Teaching Hospital, Kathmandu, Nepal.

${ }^{4}$ Om Krishna Malla, Professor, Department of Ophthalmology, Kathmandu Medical College

Teaching Hospital, Kathmandu, Nepal.

Corresponding Author

Kiran Shakya

Email: kiranshakya2001@gmail.com

\section{ABSTRACT}

\section{Background}

Phacoemulsication under topical anesthesia makes a quickest visual recovery and reduces surgical time. Topical anesthesia with supplementary intracameral lidocaine may reduce some pain during iris manipulation or iris diaphragm movement.

\section{Objective}

To study the anesthetic efficacy of topical $0.5 \%$ proparacaine hydrochloride versus combined topical - intracameral 1\% lidocaine injection during phacoemulsification surgery.

\section{Method}

Total 80 patients divided into A and B, each group having 40 patients was enrolled in this study. Phacoemulsification was performed on group A under topical anesthesia with proparacaine hydrochloride $0.5 \%$ and on group B under combined topical - intracameral injection of $0.5 c c$ $1 \%$ lidocaine. Preoperatively, all patients received counseling about the potential intraoperative visual fear. Each patient was shown visual analogue scale 10 minutes after completion of surgery and was recorded their pain score. Unco-operative patients and previous history of ocular trauma were excluded.

\section{Results}

According to visual analogue scale, on group A, 30\% felt no pain, $50 \%$ felt mild pain and $20 \%$ felt tolerable moderate pain (level 4 ) and on group $B, 80 \%$ felt no pain and $20 \%$ felt mild pain. The group A perceived pain higher than group $B(P<0.001)$. Mean operation time was 10 minutes. Most of the patients in $A$ and $B$ groups had no eye movement (Group A: $88 \%$ and Group B: $95 \%$ ). 


\section{Conclusions}

The combined topical proparacaine - intracameral injection of lidocaine anesthesia is better than topical proparacaine during phacoemulsification ensuring patients and surgeons comfort. Preoperative counseling helps the patients to focus on operating microscope light during surgery.

\section{KEYWORDS}

Intracameral, pain, phacoemulsification, preoperative counseling, topical anesthesia.

\section{INTRODUCTION}

Cataract surgery with the advent of phacoemulsication under topical anesthesia makes a quickest visual recovery and reduces surgical time. Under topical anesthesia, patients reported some pain during iris manipulation or iris diaphragm movement. Supplementary intracameral anesthesia may reduce these problems and smoothen the surgery. The rationale for using supplementary intracameral lidocaine is to provide anaesthesia for these intraocular structures. Many studies have reported that most of the patients undergoing cataract surgery may experience a multitude of visual sensations intraoperatively (Rengaraj, 2004) (Chaudhry, 2014) (Au Eong, 2000). These sensations may be affected by the type of anesthesia as patients who receive topical anesthesia (TA) are able to see more in comparison with patients who are administered region anesthesia (RA). Preoperative counseling about the potential intraoperative visual experience reduces the visual experience fear in patients having cataract surgery (Haripriya, 2011) (Shakya, 2015) (Voon, 2005).

This study focused on the anesthetic efficacy of topical proparacaine hydrochloride versus combined topical - intracameral lidocaine injection during phacoemulsification surgery.

\section{METHODS}

This randomized and comparative study was carried out at Kathmandu Medical College, Kathmandu from September 2016 to December 2016. Total eighty patients (age 50-70 years) were divided into two groups, A and B. Every second patient was group as B. Informed consent was obtained from every subject before their enrollment in the study. Group A (40 patients) under topical anesthesia with proparacaine hydrochloride $0.5 \%$ and group B (40 patients) under topical anesthesia along with intracameral infiltration $0.5 \mathrm{cc}$ of $1 \%$ lidocaine underwent phacoemulsification surgery with foldable intraocular lens (Kale, 2012). Preoperatively all patients received counseling on the potential intraoperative visual experience viz light perception, fingers, instruments and gush of water (Chaudhry, 2014) (Haripriya, 2011) (Shakya, 2015) (Voon, 2005). Unco-operative patients, previous history of ocular trauma and corneal opacities were excluded from the study. Ethical clearance was obtained from the Institutional Review Committee.

\section{Surgical method}


All patients were advised to instill Ofloxacin eye drop four times one day prior to surgery. A single drop of topical anaesthesia using Proparacaine hydrochloride $0.5 \%$ eye drop was instilled three times for every two minutes before surgery. The patients were brought to the operating room where the eye was painted with betadine and draped for cataract surgery. All surgeries were performed by a single surgeon (KS). After ascertaining painlessness to patient by pinching conjunctiva of operating eye with plain forceps, the patient was instructed to fix the eye at light of operating microscope. The clear corneal tunnel incision and side port were fashioned. $0.5 \mathrm{cc}$ of $1 \%$ preservative free lidocaine was injected into anterior chamber through side port for group B. A continuous curvilinear capsulorrhexis was performed under a viscoelastic material (HPMC). The lens nucleus was mobilized using a balanced salt solution and a blunt hydrodissection cannula. Phacoemulsification was performed using the Oertli (Catarhex) phacoemulsifier with the phacochop and endocapsular techniques by an operating microscope, CarlZeiss-S7. A foldable acrylic IOL with a $6 \mathrm{~mm}$ phacoemulsification lens was inserted under the viscoelastic material through a $2.8 \mathrm{~mm}$ opening. The viscoelastic material was aspirated. The wound was hydrated and an approximate physiological intraocular pressure was restored with a balanced salt solution injection through a side port. An intra-cameral injection of Cefuroxime $1 \mathrm{mg}$ was given at the conclusion of the surgery.

\section{Pain assessment}

After 10 minutes of completion of surgery, each patient was shown a visual analogue scale with numeric and descriptive ratings from 0 (no pain) to 10 (severe pain) as described by Stevens (Stevens, 1992). Patients were asked to use this 10-point scale to rate the level of pain felt during the operation. In addition, any verbal expression of pain that patients made during the operation (eg, on manipulation of an iris) was recorded. Patients were asked to inform the surgeon if they experienced any pain at any point of the surgery. If so, additional anesthesia was given. Any ocular motility during the time of surgery, surgical complications and postoperative use of analgesics were recorded. The patient started post-operative prescription of Ofloxacin $0.3 \%$ eye drops four times daily and Prednisolone acetate $1 \%$ eye drops six times daily. All the patients' appointment was made for next day, one week and one month after surgery.

Data were entered and analyzed using SPSS version 20.0. A p-value of $<0.05$ was considered statistically significant.

\section{RESULTS}

Thirty four $(42.5 \%)$ of them were men and $46(57.5 \%)$ were women. $58 \%$ of patients were above 60 years. According to visual analogue scale, on group A, 30\% felt no pain, $50 \%$ felt mild pain and 20\% felt tolerable moderate pain (level 4) and on group B, 80\% felt no pain and 20\% felt mild pain (Table1 and Table 2). The group A perceived pain higher than group B ( $\mathrm{P}<0.001)$. The mean pain score was 1.9 ( $\mathrm{SD} \pm 1.52$ ) in group A and 0.35 ( $\mathrm{SD} \pm 0.73$ )in group B (Table 3 and Figure 1). Mean operation time was 10 minutes. Most of the patients in A and B groups had 
no eye movement (Group A: $88 \%$ and Group B: 95\%). The patients on group A used postoperative analgesics than those in group $\mathrm{B}(\mathrm{P}<0.001)$.

Table1. Characteristics of 80 Patients randomly assigned to receive Topical Proparacain with or without Intracameral Lidocaine for Phacoemulsification.

\begin{tabular}{|c|c|c|c|c|c|}
\hline$\overline{\text { Variables }}$ & $\begin{array}{ll}\text { Group } & \mathbf{A}(40 \\
\text { patients }) & \end{array}$ & $\begin{array}{l}\text { Percentage } \\
(\%)\end{array}$ & $\begin{array}{ll}\text { Group } & \text { B } \\
(40 & \\
\text { patients }) & \end{array}$ & $\begin{array}{l}\text { Percentage } \\
(\%)\end{array}$ & $\begin{array}{l}\text { Level of } \\
\text { Significance } \\
\text { (P) }\end{array}$ \\
\hline \multirow[t]{2}{*}{ Age } & $<60$ & 40 & & 45 & \\
\hline & $>60$ & 60 & & 55 & \\
\hline \multirow{2}{*}{$\begin{array}{l}\text { Preoperative } \\
\text { visual acuity }\end{array}$} & Better than $6 / 18$ & 35 & & 37.5 & \\
\hline & Less than $6 / 18$ & 65 & & 62.5 & \\
\hline \multirow{3}{*}{$\begin{array}{l}\text { Visual analog } \\
\text { scale }\end{array}$} & No pain & 30 & No pain & 80 & $<0.001$ \\
\hline & Mild pain & 50 & Mild pain & 20 & \\
\hline & $\begin{array}{l}\text { Moderate pain } \\
\quad \text { (level 4) }\end{array}$ & 20 & $\begin{array}{l}\text { Moderate } \\
\text { pain }\end{array}$ & 0 & \\
\hline $\begin{array}{l}\text { No eyeball } \\
\text { Movement }\end{array}$ & & 88 & & 95 & 0.057 \\
\hline $\begin{array}{l}\text { Postoperative } \\
\text { oral analgesics }\end{array}$ & & 20 & & 5 & $<0.001$ \\
\hline
\end{tabular}

Table 2. Characteristics of pain score according to visual analog scale.

\begin{tabular}{|c|c|c|c|c|c|}
\hline \multicolumn{3}{|c|}{ Group A (40 patients) } & \multicolumn{3}{|c|}{ Group B (40 patients) } \\
\hline \multicolumn{2}{|c|}{ Visual analog scale } & \multirow{2}{*}{$\begin{array}{l}\text { Percentage } \\
(\%) \\
30\end{array}$} & \multicolumn{2}{|c|}{ Visual analog scale } & \multirow{2}{*}{$\begin{array}{l}\text { Percentage } \\
(\%) \\
80\end{array}$} \\
\hline No pain & 0 & & No pain & 0 & \\
\hline \multirow[t]{3}{*}{ Mild pain } & 1 & 10 & \multirow[t]{3}{*}{ Mild pain } & 1 & 20 \\
\hline & 2 & 20 & & 2 & 0 \\
\hline & 3 & 20 & & 3 & 0 \\
\hline $\begin{array}{l}\text { Moderate } \\
\text { pain }\end{array}$ & 4 & 20 & $\begin{array}{l}\text { Moderate } \\
\text { pain }\end{array}$ & 4 & 0 \\
\hline
\end{tabular}

Table 3.Pain score (scale of $0-10$ ).

\begin{tabular}{|l|c|c|}
\hline & Group A & Group B \\
\hline Mean of pain score & $1.9(\mathrm{SD} \pm 1.52)$ & $0.35(\mathrm{SD} \pm 0.73)$ \\
\hline Range & $0-4$ & $0-1$ \\
\hline
\end{tabular}




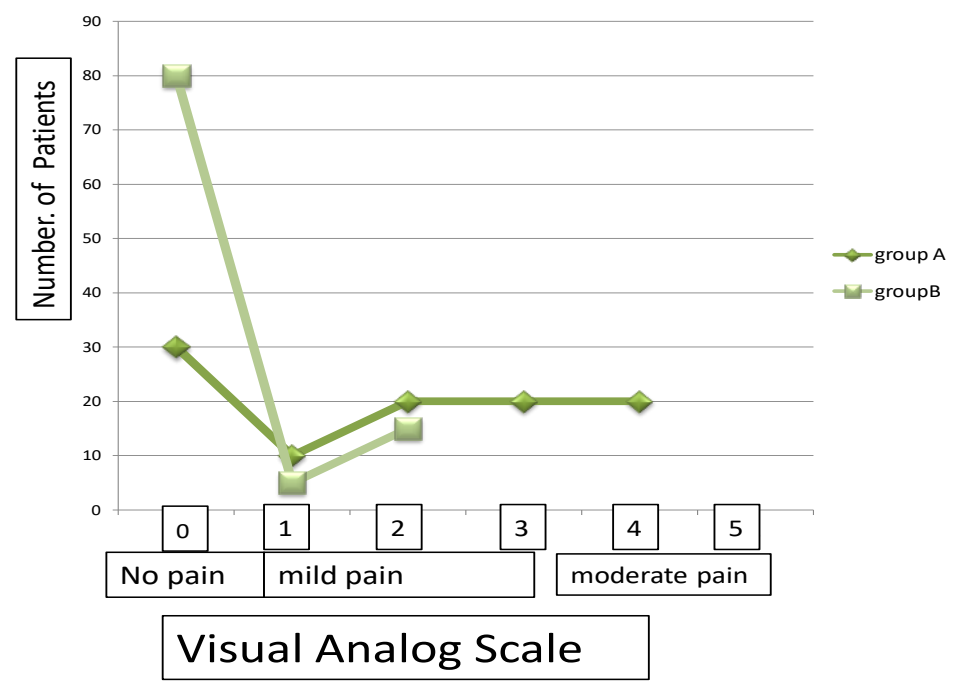

Figure 1. Shows pain score among topical only group (A) and combined topicalintracameral lidocaine group (B).

\section{DISCUSSION}

Topical anaesthesia has become an increasingly popular option in modern phacoemulsification surgery as the patients benefit from a quickest visual recovery. But the patients experience intraoperative visual sensation and some pain during iris-diaphragm movement or iris manipulation. Preoperative counselling about the potential intraoperative visual experience alleviates the visual experience fear in patients having cataract surgery and many surgeons use intracameral lidocaine as a supplement to topical anaesthesia which significantly reduces intraoperative pain perception when compared to the use of topical anaesthesia alone.

In our study, there was a significant reduction in pain perception in the intracameral lidocaine group than in the topical proparacaine only group $(\mathrm{P}<0.001)$. Tseng $\mathrm{H}$ and his associates shows the difference between the pain scores for the placebo group (topical anesthesia with intracameral balanced salt solution [group 1]) and the interventional group (combined topical-intracameral anesthesia [group 2]) was statistically significant $(\mathrm{P}=0.0053)$ Combined topical and intracameral administration of lidocaine can further minimize intraoperative discomfort (Tseng, 1998). Similarly, Kale DN and co-workers found that the intracameral infiltration of $2 \%$ lidocaine injection with topical anesthesia is superior to topical anesthesia with proparacaine hydrochloride alone during phacoemulsification (Kale, 2012). Gills and Koch reported that irrigation of the anterior chamber with unpreserved lidocaine alleviated the intraocular discomfort of some patients undergoing cataract extraction and implantation of an IOL while under topical anesthesia (Gills, 1997) (Koch, 1997). 
Thirty percent of patients in group A and $80 \%$ in group B leveled a score 0 in visual analog scale. Tseng $\mathrm{H}$ et al ninety percent of patients in group 1 and $95 \%$ in group 2 assigned a score of 0 or 1 to the level of intraoperative discomfort (Tseng, 1998).

In this study, the mean pain score was $1.9(\mathrm{SD} \pm 1.52)$ in group $\mathrm{A}$ and $0.35(\mathrm{SD} \pm 0.73)$ in group B. Patel et al reported that the mean pain score of 0.41 for patients (Patel, 1996).

All patients in group B experienced no ocular discomfort immediately after the injection of $0.5 \mathrm{cc}$ of $1 \%$ preservative free lidocaine into the anterior chamber. Postoperatively, slit-lamp biomicroscopic examination showed no evidence of corneal pathology, edema, thickening, or other toxicity, nor did any patients in our study have unexplained iritis or other unusual intraocular inflammation developed. $0.5 \mathrm{cc}$ of $1 \%$ preservative free lidocaine seems to be safe for the cornea, the anterior chamber, and the retina (Gills, 1997).

\section{CONCLUSIONS}

The combined topical proparacaine - intracameral injection of lidocaine anesthesia is better than topical proparacaine only during phacoemulsification ensuring patients and surgeons comfort. Preoperative counseling helps the patients to focus on operating microscope light during surgery and alleviates the visual experience fear in patients having cataract surgery.

\section{REFERENCES}

1. Au Eong, K.G., Low, C.H., Heng, W.J. (2000). Subjective visual experience during phacoemulsification and intraocular lens implantation under topical anesthesia. Ophthalmology, 107(2):248-250.

2. Chaudhry, T.A., Aqil, A., Aziz, K., Javed, A.A., Tauqir, M.Z., Ahmad, K. (2014). Patients' visual experience during phacoemulsification cataract surgery and associated fear. BMC Research Notes, 20 (7), 663.

3. Gills, J.P., Cherchio, M., Raanan, M.G. (1997). Unpreserved lidocaine to control discomfort during cataract surgery using topical anesthesia. Journal of Cataract Refractive Surgery, 23, 545-50.

4. Haripriya, A., Tan, C.S., Venkatesh, R., Aravind, S., Dev, A., Au Eong, K.G. (2011). Effect of preoperative counseling on fear from visual sensations during phacoemulsification under topical anesthesia. Journal of Cataract Refractive Surgery, 37(5), 814-8.

5. Kale, D.N., Chingsuingamba, Y. (2012). Phacoemulsification under topical anesthesia alone versus topical anesthesia with intracameral lidocaine injection. IOSR Journal of Dental and Medical Sciences, 3, 08-12.

6. Koch, P.S. (1997). Anterior chamber irrigation with unpreserved lidocaine $1 \%$ for anesthesia during cataract surgery. Journal of Cataract Refractive Surgery, 23, 551-4.

7. Patel, B.C.K., Burns, T.A., Crandall, A et al (1996). A comparison of topical and retrobulbar anesthesia for cataract surgery. Ophthalmology, 3, 1196-203. 
8. Rengaraj, V., Radhakrishnan, M., Au Eong, K.G., Saw, S.M., Srinivasan, A., Mathew, J., Ramasamy, K., Prajna, N.V. (2004). Visual experience during phacoemulsification under topical versus retrobulbar anesthesia: results of a prospective, randomized, controlled trial. American Journal of Ophthalmology, 138(5), 782-787.

9. Shakya, K. P., Malla, O.K. et al (2015). Intraoperative visual experience and preoperative counselling during phacoemulsification under topical anaesthesia. Journal of Kathmandu Medical College, 4, 45-49.

10. Stevens, J.D. (1992). A new local anaesthesia technique for cataract extraction by one quadrant sub-Tenon's infiltration. British Journal of Ophthalmology, 76, 670-4.

11. Tseng, H., Chen, F.K. (2007). A randomized clinical trial of combined topicalintracameral anesthesia in cataract surgery. Ophthalmology, 105, 2007-2011.

12. Voon, L.W., Au Eong, K.G., Saw, S.M., Verma, D., Laude, A. (2005). Effect of preoperative counseling on patient fear from the visual experience during phacoemulsification under topical anesthesia: multicenter randomized clinical trial. Journal of Cataract Refractive Surgery, 31(10), 1966-1969. 